\title{
Preparation of Polymer Composite Particles by Phase Separation Followed by Suspension Polymerization
}

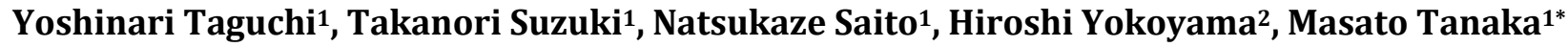 \\ ${ }^{1}$ Graduate School of Science and Technology, Niigata University, Niigata-shi, Japan \\ ${ }^{2}$ Niigata University of Management, Kamo, Japan \\ Email: *tanaka@eng.niigata-u.ac.jp
}

How to cite this paper: Taguchi, Y., Suzuki, T., Saito, N., Yokoyama, H. and Tanaka, M. (2017) Preparation of Polymer Composite Particles by Phase Separation Followed by Suspension Polymerization. Open Journal of Composite Materials, 7, 1-13.

https://doi.org/10.4236/ojcm.2017.71001

Received: December 15, 2016

Accepted: January 13, 2017

Published: January 16, 2017

Copyright $\odot 2017$ by authors and Scientific Research Publishing Inc. This work is licensed under the Creative Commons Attribution International License (CC BY 4.0).

http://creativecommons.org/licenses/by/4.0/

\begin{abstract}
The novel method for preparing the polymer composite particles has been developed. It was tried to prepare polymer composite particles composed of polystyrene and carbon black with the phase separation method followed by suspension polymerization. In order to prepare the polymer composite particles with the more uniform diameter, the styrene monomer droplets containing carbon black were formed with phase separation emulsification in which ethyl alcohol and water were used as the good solvent and the poor solvent for styrene monomer, respectively. In the experiment, the surfactant species and their concentrations, the pouring velocity of water and the weight ratio of carbon black to styrene monomer were mainly changed. Water was poured at the given pouring velocity into ethyl alcohol in which styrene monomer and an initiator were dissolved and carbon black was dispersed beforehand. The spherical polymer composite particles containing carbon black were prepared with Tween 20 and Tween 80 of nonionic surfactants and the irregular polymer composite particles were prepared with PVA, SDS and Kotamine. The diameters of polymer composite particles increased with the pouring velocity of water and with the weight ratio of carbon black to styrene monomer.
\end{abstract}

\section{Keywords}

Polymer Composite Particles, Phase Separation, Suspension Polymerization,

Polystyrene Beads, Carbon Black, Amphiphilic Solvent

\section{Introduction}

Polymer/solid powder composite particles have attracted tremendous attention for their potential in improving polymer properties and dispersibility and solvent resistance of solid powder in the organic solvent [1] [2] [3]. 
A lot of approaches have been developed for preparing polymer/solid powder composite particles, such as the in-situ polymerization method [3] [4], the dry coating method [5] [6] and the physical chemistry method [7] [8].

The in-situ polymerization method among them is based on the formation of polymer particles while containing solid powder, which is dispersed in monomer or the continuous phase beforehand.

For example, as the typical in-situ polymerization methods, there are the suspension polymerization method [9], the mini emulsion polymerization method [10] [11], the soap free emulsion polymerization method [12] and the dispersion polymerization method [13].

The suspension polymerization method and the mini emulsion polymerization method are suitable to preparing the polymer composite particles containing a lot of solid powder at once, and the soap free polymerization method and the dispersion polymerization method are suitable to preparing the polymer composite particles containing a solid powder particle.

However, with regard to the uniformity of the polymer composite particle diameters, the suspension polymerization method is well known to prepare the polymer composite particles with the broder diameter distribution.

In order to prepare the polymer composite particles with the more uniform diameters by use of the suspension polymerization method, the SPG emulsification method [14], the microchannel emulsification method [15] and the high pressure homogenization emulsification method [16] have been applied.

However, these preparation methods are complex of the operation and not suitable to the mass production.

While, the phase separation emulsification method can form the liquid droplets with the uniform diameter by controlling a few experimental conditions such as the pouring velocity of poor solvent and the surfactant species and their concentrations [17] [18].

In this study, it was tried to prepare the polymer composite particles with the more uniform diameter and with the high content of solid powder by using phase separation followed by suspension polymerization.

Namely, it may be expected that the monomer droplets with the more uniform diameter and with the higher content could be prepared with the phase separation process and then, mass production of polymer composite particles could be performed with conventional suspension polymerization.

The purposes of this work are to try to prepare the polymer composite particles composed of polystyrene and carbon black with the preparation method presented in this study and to investigate how the operation conditions such as the pouring velocity of poor solvent, the surfactant species and their concentrations and the carbon concentration affect the characteristics of polymer composite particles.

\section{Experimental}

\subsection{Materials}

Materials used to prepare the polymer composite particles (PCP) composed of polystyrene and carbon black were as follows. Styrene monomer (St) (Wako. Pure Chemical 
Id., Ltd, Tokyo) as polymerizable monomer and 2,2'-Azobis (2,4-dimethylvaleronitrile) (V-65) (Wako. Pure Chemical Id., Ltd, Tokyo) as an initiator were used. The inhibitor dissolved in St was removed by extraction with $\mathrm{NaOH}$ (Wako. Pure Chemical Id., Ltd, Tokyo) aqueous solution beforehand.

Ethylalcohol (EtOH) (Wako Pure Chemical Id., Ltd., Tokyo) was used as a good solvent for St. Distilled water was used as the continuous phase and the poor solvent for St, respectively.

As water soluble surfactants or stabilizers, the following materials were used. Polyoxyethylenesorbitanmonolaurate (Tween 20: Tokyo Kasei Kogyo Ind., Ltd, Tokyo) and polyoxyethylenesorbitanmonooleate (Tween 80: Tokyo Kasei Kogyo Ind., Ltd, Tokyo) were adopted as the nonionic surfactants. Sulfuric acid dodecyl sodium (SDS: Tokyo Kasei Kogyo Ind., Ltd, Tokyo) was used as an anionic surfactant. Lauryltrimethylanmoium chloride (Kotamine 24: Kao Ltd. Tokyo) was used as a cationic surfactant and Polyvinylalcohol (PVA MW = 500 Tokyo Kasei Ind., Ltd., Tokyo) was used as a stabilizer for comparison.

As carbon black (CB), carbon black \#960 (diameter $=16 \mathrm{~nm}$, surface area $=260 \mathrm{~m}^{2} / \mathrm{g}$, $\mathrm{pH}=9.5$, Mitsubishi Chemical Ltd., Tokyo) was used.

\subsection{Preparation of Polymer Composite Particles}

Figure 1 shows the flow chart for preparing PCP with the preparation method presented in this study.

St, CB and V-65 were added in EtOH and then, stirred for 10 min with the rotarstater homogenizer to uniformly disperse $\mathrm{CB}$ and to form the $(\mathrm{S} / \mathrm{O})$ dispersion.

Then, the aqueous solution dissolving the surfactant was poured into the $(\mathrm{S} / \mathrm{O})$ dispersion with the syring pump under room temperature and stirring with magnetic stirrer.

On increasing the poured volume of surfactant aqueous solution, the St droplets came to be formed by phase separation and then, the $(\mathrm{S} / \mathrm{O})$ dispersion changed to the

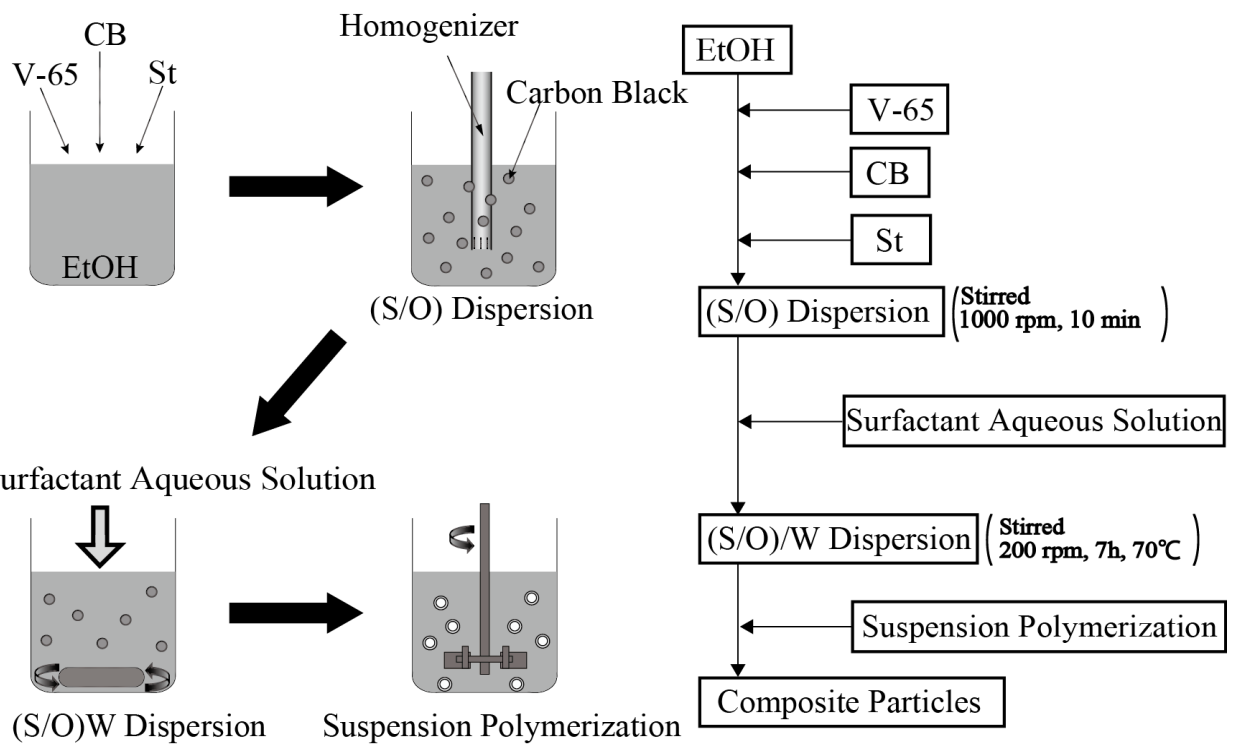

Figure 1. Flow chart for preparing polymer composite particles. 
(S/O)/W dispersion by phase inversion.

In the formation of the St droplets, it is expected that CB could be enfolded into the St droplets. At the phase separation process stated above, EtOH played an important role as an amphiphilic solvent.

After the formation of the $(\mathrm{S} / \mathrm{O}) / \mathrm{W}$ dispersion, suspension polymerization was performed for $7 \mathrm{~h}$ under the conditions such as $70^{\circ} \mathrm{C}$ and stirring with the six bladed impeller.

PCPs prepared thus were washed twice with distilled water and dried under room temperature.

In this fundamental experiment, the surfactant species and their concentrations $(C)$, the pouring velocity $(\mathrm{Ve})$ of surfactant aqueous solution and the weight ratio $(R=$ $W_{d}\left(W_{s}\right)$ of $\mathrm{CB}\left(W_{c}\right)$ to St $\left(W_{s}\right)$ were mainly changed.

Figure 2 shows the schematic diagram of experimental apparatus.

The reactor, which was the separable flask with the effective volume of $500 \mathrm{cc}$, was set in the thermostated water bath to keep the reaction temperature $\left(70^{\circ} \mathrm{C}\right)$ constant at the suspension polymerization process. The six bladed turbine impeller with the diameter of $5.0 \mathrm{~cm}$ was set at one third of the liquid depth from the bottom.

The four baffles ( $80 \mathrm{~mm}$ in length and $8 \mathrm{~mm}$ in width) made of aluminum plate were set to prevent air from entraining as shown in Figure 2.

Table 1 shows the experimental conditions used in this study.

\section{Characterization}

\subsection{Observation of PCP}

PCPs were observed by scanning electron microscope (SEM: JSM-5800, JEOL Ltd., Tokyo, Japan) and taken the SEM photographs. From the SEM photographs, the whole, the shape and the surface of a PCP were observed.

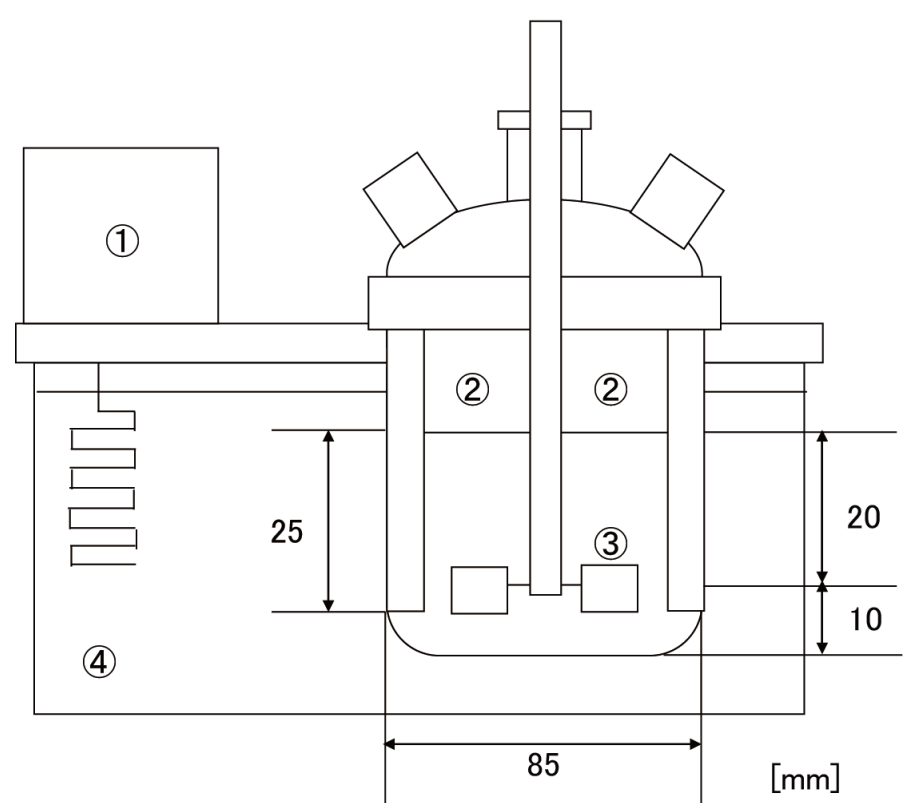

Figure 2. Schematic diagram of experimental apparatus.
(1) Thermostat

(2) Baffle

(3) Impeller

(4) Water Bath

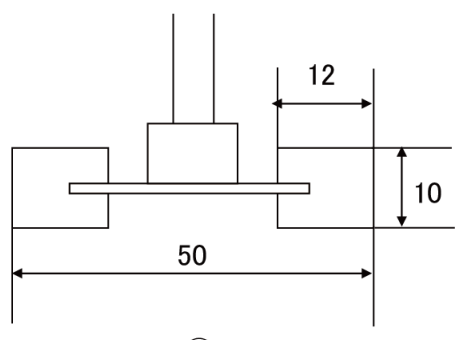

(3) 
Table 1. Experimental conditions.

\begin{tabular}{|c|c|c|}
\hline \multicolumn{2}{|c|}{$<$ EtOH solution $>$} & \multirow{2}{*}{$\begin{array}{r}<\text { Formation of }(\mathrm{S} / \mathrm{O}) \text { dispersion }> \\
\qquad N r=10,000 \mathrm{rpm}\end{array}$} \\
\hline $\mathrm{EtOH}$ & $4.0 \mathrm{~g}$ & \\
\hline $\mathrm{CB}$ & $W c=0.5 \mathrm{~g}$ & $t=10 \mathrm{~min}$ \\
\hline St & $W s=0.5-10 \mathrm{~g}$ & \\
\hline V-65 & $1.0 \mathrm{~g}$ & \\
\hline$<$ Water Phase $>$ & & $<$ Suspension polymerization $>$ \\
\hline Total volume & $300 \mathrm{ml}$ & $N r=200 \mathrm{rpm}$ \\
\hline Pouring Velocity & $V e=10,25,50,100 \mathrm{ml} / \mathrm{h}$ & $T=70^{\circ} \mathrm{C}$ \\
\hline$<$ Surfactant $>$ & & $t=7 \mathrm{~h}$ \\
\hline Tween 20 & & $<$ Weight ratio of $\mathrm{CB}$ to $\mathrm{St}>$ \\
\hline Tween 80 & & $R=1 / 1,1 / 5,1 / 10,1 / 20$ \\
\hline \multicolumn{3}{|l|}{ Kotamin Concentration } \\
\hline SDS & $C=0.5,1.0,1.5,2.0 \mathrm{wt} \%$ & \\
\hline PVA & & \\
\hline
\end{tabular}

\subsection{Diameter Distribution, Mean Diameter and $\zeta$-Potentials}

The diameter distributions and mean diameters of PCPs were measured by particle size analyzer (SALD-3000, Shimazu Seisakusho, Co, Ltd., Kyoto, Japan). Here, the mean diameters (dp) are the Sauter mean diameters.

The $\zeta$-potentials of $\mathrm{CB}$, the St droplets and PCP were measured by particle size analyzer (ELS Z-2; Otsuka Electronics, Co., Ltd., Tokyo, Japan).

\subsection{Content}

The content $(M)$ of $\mathrm{CB}$ contained in PCP was measured as follows.

PCPs of the given weight were added in St $(30 \mathrm{ml})$ and stirred with the magnetic stirrer to dissolve polystyrene.

Then, $\mathrm{CB}$ was separated by the filter paper from the $\mathrm{CB}$ slurry, washed twice with $\mathrm{EtOH}$, dried under room temperature and measured the weight.

The content $(M)$ of $\mathrm{CB}$ was calculated from the measured weight $\left(W_{p}\right)$ of PCP and that $\left(M_{c}\right)$ of $\mathrm{CB}$ according to the following equation.

$$
M=\frac{\text { Weight }\left(W_{c}\right) \text { of CB Contained }}{\text { Weight }\left(W_{p}\right) \text { of PCP }}
$$

\section{Results and Discussion}

\subsection{Effect of Surfactant Species}

The $\zeta$-potentials and the dispersing behavior of CB and the St droplets are strongly affected by the surfactant species and their concentrations [19] [20].

As a result, the formation mechanism, the shape and the diameter of PCP may be different depending on the surfactant species and their concentrations.

Figure 3 shows the SEM photographs of PCPs prepared with each surfactant under the experimental conditions such as $W_{c}=0.5 \mathrm{~g}, W_{s}=5.0 \mathrm{~g}, C=1.0 \mathrm{wt} \%$ and $V e=25$ $\mathrm{ml} / \mathrm{h}$. The morphology and the diameters of PCPs are significantly different depending 

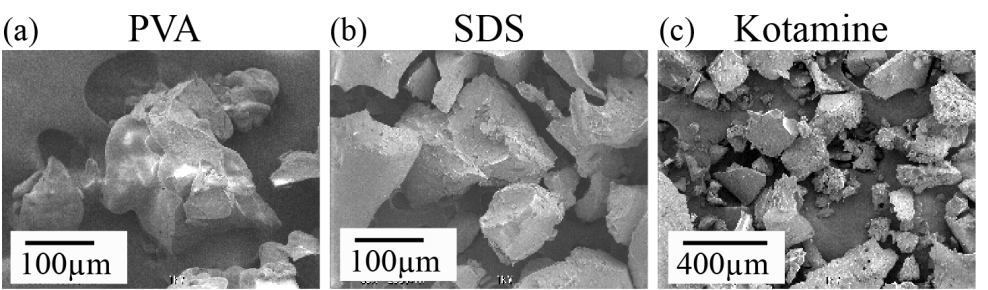

(d) Tween 80

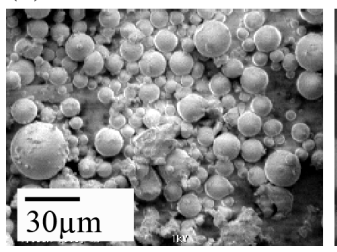

(e) Tween 20

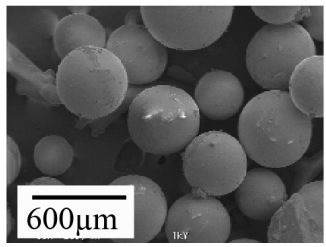

$$
\begin{aligned}
W c & =0.5 \mathrm{~g} \\
W s & =5.0 \mathrm{~g} \\
C & =1.0 \mathrm{wt} \% \\
V e & =25 \mathrm{ml} / \mathrm{h}
\end{aligned}
$$

Figure 3. SEM Photographs of polymer composites particles (effect of surfactant species).

on the surfactant species.

The sound spherical PCPs could be prepared with Tween 20 (Figure 3(e)) and Tween 80 (Figure 3(d)). On the other hand, the irregular PCPs were prepared with PVA (Figure 3(a)), SDS (Figure 3(b)) and Kotamine (Figure 3(c)).

Why the morphology of PCP is different depending on the surfactant species may be due to the fact that affinity between the St droplets and CB and the coalescence mechanism between the St droplets are different depending on the surfactant species.

The formation mechanism of PCP will be discussed in detail later.

As Tween 80 among these surfactant species could prepare PCPs with the desired size and morphology and became the dispersion more stable than Tween 20, hereafter the effects of the operational conditions on the characteristics of PCP were investigated by using only Tween 80 .

\subsection{Effects of Concentration of Surfactant}

Figure 4 shows the dependences of the mean diameter (dp) and the CV value of PCPs on the concentration $(C$ ) of surfactant (Tween 80 ) together with the SEM photographs.

The mean diameter decreased with the concentration from ca. $40 \mu \mathrm{m}$ at $C=0.5 \mathrm{wt} \%$ to ca. $10 \mu \mathrm{m}$ at $C=1.5 \mathrm{wt} \%$ and the $\mathrm{CV}$ value decreased with the concentration from ca. 1.8 at $C=0.5 \mathrm{wt} \%$ to ca. 0.5 at $C=1.0 \mathrm{wt} \%$ and then, increased slightly.

From these results, it was found that the higher the concentration of surfactant, the smaller and more uniform PCPs could be prepared.

At the lower concentration of surfactant, $\mathrm{CB}$ and the $(\mathrm{S} / \mathrm{O})$ droplets may be unstable and easy to flocculate and to coalesce, respectively. As a result, PCPs with the larger and broader diameter distribution may be prepared.

In order to increase the stability of both $\mathrm{CB}$ in the $(\mathrm{S} / \mathrm{O})$ dispersion and the $(\mathrm{S} / \mathrm{O})$ droplets in the $(\mathrm{S} / \mathrm{O}) / \mathrm{W}$ dispersion, it was tired to prepare PCP by adding a part $(10 \mathrm{cc})$ of surfactant aqueous solution in EtOH beforehand.

In this operation, it was confirmed that the St droplets were never formed by adding the surfactant aqueous solution of $10 \mathrm{cc}$.

Figure 5 shows the effect of prior addition of surfactant aqueous solution on the 
(a)

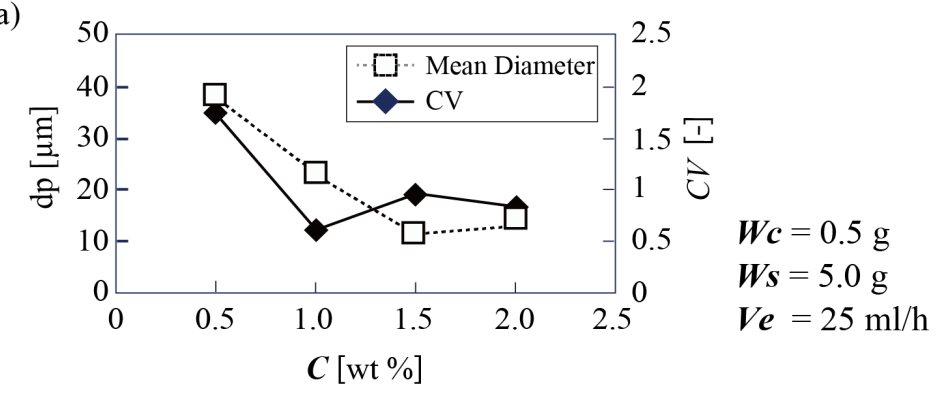

(b) $C=0.5 \mathrm{wt} \%$

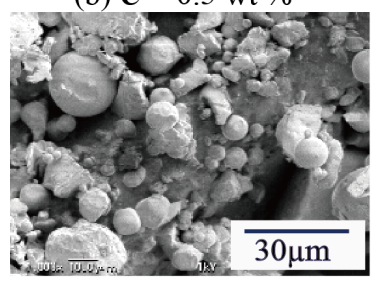

(c) $C=1.5 \mathrm{wt} \%$

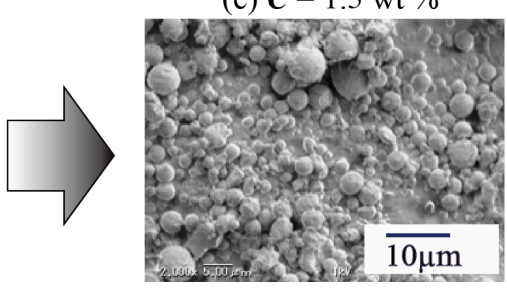

Figure 4. Effect of surfacntat concentratin and SEM Photographs.

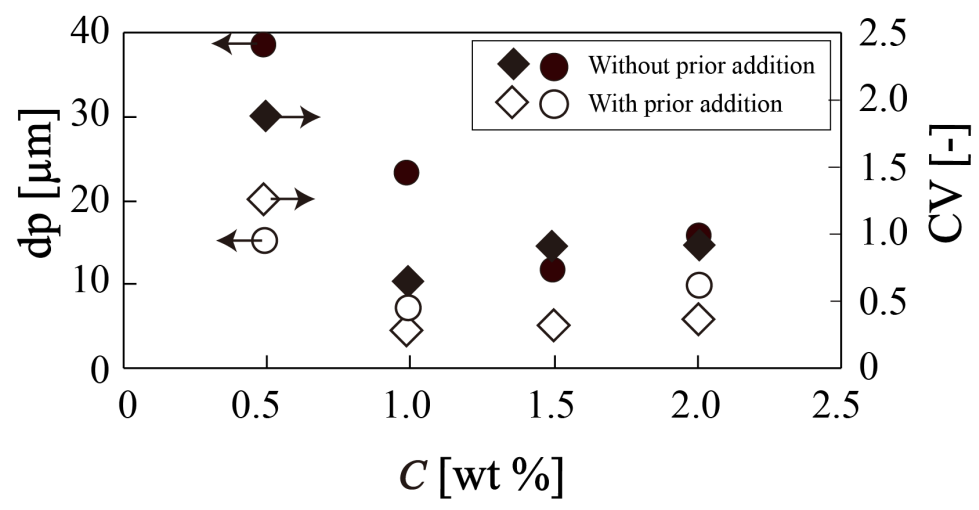

$$
W c=0.5 \mathrm{~g}, W s=5.0 \mathrm{~g}, V e=25 \mathrm{ml} / \mathrm{h}
$$

Figure 5. Effect of prior addition of surfactant aqueous solution.

mean diameter and the $\mathrm{CV}$ value of PCPs.

It was found that the mean diameters with prior addition were smaller than those without prior addition. For example, the diameter decreased from ca. $39.0 \mu \mathrm{m}$ without prior addition to ca. $15.0 \mu \mathrm{m}$ with prior addition at $C=0.5 \mathrm{wt} \%$ and from ca. $15.0 \mu \mathrm{m}$ without prior addition to ca. $10.0 \mu \mathrm{m}$ with prior addition at $C=2.0 \mathrm{wt} \%$. On the other hand, all the CV values with prior addition became smaller than those without prior addition, namely, the PCPs with the more uniform diameters could be prepared. For example, the $\mathrm{CV}$ value decreased from ca. 1.0 without prior addition to ca. 0.3 with prior addition at $\mathrm{C}=2.0 \mathrm{wt} \%$.

On comparing these results with the results $(\mathrm{CV}=0.5-1.2)$ by the conventional suspension polymerization method [21] [22], PCPs with the considerable uniform diameters could be prepared with the preparation method presented in this study.

This result may be due to the fact that the St droplets with the more uniform diameters could be formed by phase separation and the stability of both $\mathrm{CB}$ in the $(\mathrm{S} / \mathrm{O})$ dispersion and the St droplets in the $(\mathrm{S} / \mathrm{O}) / \mathrm{W}$ dispersion was increased by the prior addition of surfactant aqueous solution. 


\subsection{Effect of Weight Ratio of CB to St}

The weight ratio $(R)$ of $\mathrm{CB}$ to St, namely, the $\mathrm{CB}$ concentration must affect the characteristics of PCP such as the morphology, the particle diameter and the content.

Figure 6 shows the effect of the weight ratio $(R)$ of $\mathrm{CB}$ to St on the mean diameter and the $\mathrm{CV}$ value of PCP. On decreasing $R$ (namely increasing $\mathrm{St}$ ), the mean diameter increased and the $\mathrm{CV}$ value decreased.

For example, the mean diameter increased from ca. $4.0 \mu \mathrm{m}$ at $R=1 / 1$ to ca. $=18 \mu \mathrm{m}$ at $R=1 / 20$, while the $\mathrm{CV}$ value decreased from 1.4 at $R=1 / 1$ to 0.7 at $R=1 / 20$.

Figure 7 shows the SEM photographs of PCPs prepared by changing $R$. It was found that PCPs became larger and more spherical with decreasing $R$.

As the number concentration of the St droplets may increase with decreasing $R$ (increasing St), coalescence between the St droplets may become active and the volume of a St droplet containing CB may increase. As a result, the shape of St droplets containing $\mathrm{CB}$ is easy to become spherical.

\subsection{Effect of Pouring Velocity of Surfactant Aqueous Solution}

The pouring velocity of the surfactant aqueous solution must affect the formation velocity of the St droplets, as a result, the mechanism containing CB.

Figure 8 shows the effect of the pouring velocity ( $\mathrm{Ve}$ ) of the surfactant aqueous solution on the mean diameter and the CV value of PCP.

The mean diameter increased from ca. $2.5 \mu \mathrm{m}$ at $V e=10 \mathrm{ml} / \mathrm{h}$ to ca. $15 \mu \mathrm{m}$ at $V e=$

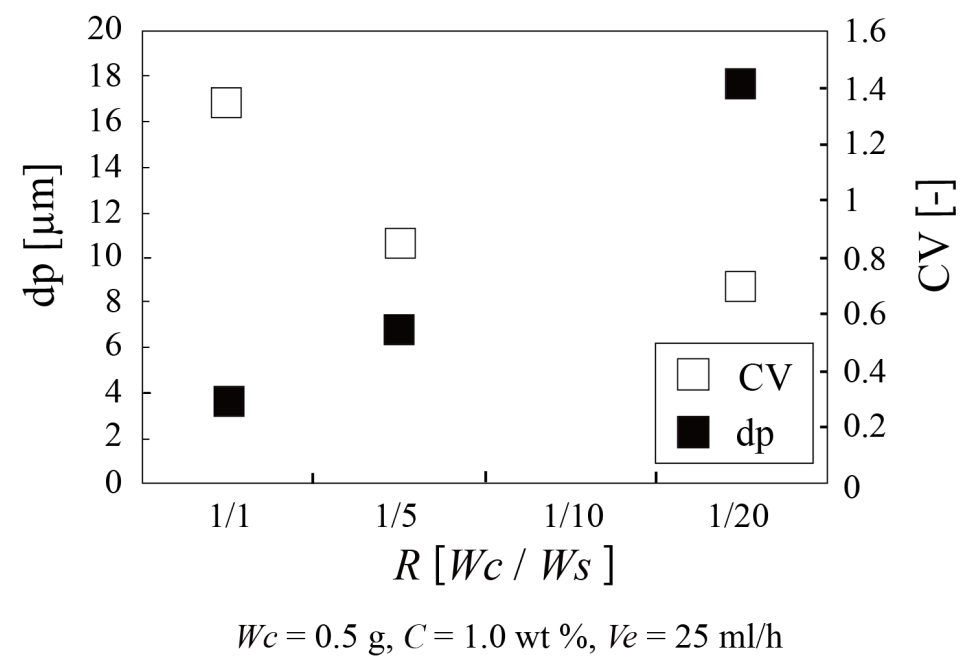

Figure 6. Effect of weight ratio of $\mathrm{CB}$ to St.
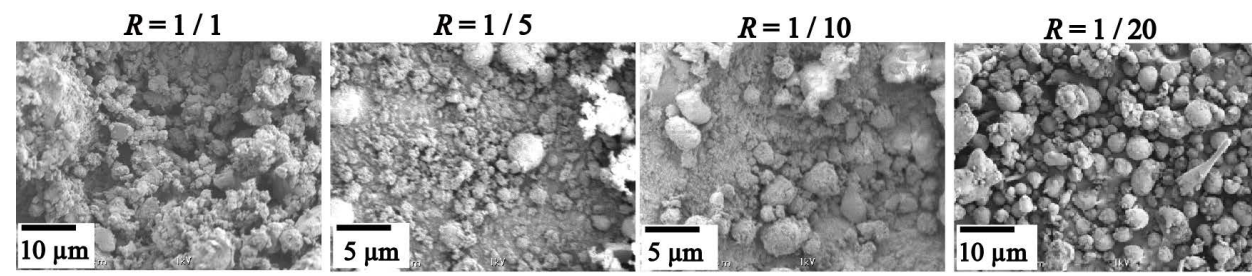

$W c=0.5 \mathrm{~g}, C=1.0 \mathrm{wt} \%, V e=25 \mathrm{ml} / \mathrm{h}$

Figure 7. SEM photographs of polymer composite particles prepared by changing $R$. 


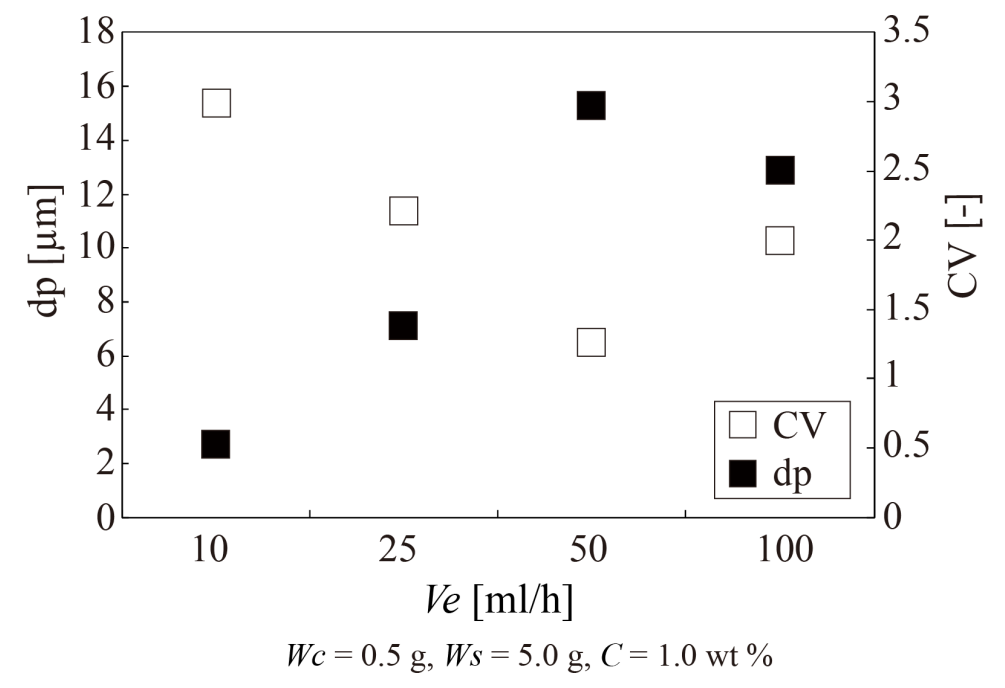

Figure 8. Effect of pouring velocity of surfactant aqueous solution.

$50 \mathrm{ml} / \mathrm{hand}$ then, decreased to $13.0 \mu \mathrm{m}$ at $V e=100 \mathrm{ml} / \mathrm{h}$.

On the other hand, the CV value decreased from 3.0 at $V e=10 \mathrm{ml} / \mathrm{h}$ to 1.2 at $V e=50$ $\mathrm{ml} / \mathrm{h}$ and then, increased to 2.0 at $V e=100 \mathrm{ml} / \mathrm{h}$.

As the formation velocity of the St droplets must increase with the pouring velocity, coalescence between the St droplets with the various diameters may become active, as a result, PCPs may become larger and more uniform. However, the larger droplets may be easy broken up.

\subsection{Effect of Operation Conditions on Content}

The content of CB contained in PCP may be affected by the formation mechanism, namely the operational conditions such as the surfactant species and their concentrations, the pouring velocity of surfactant aqueous solutions and the weight ratio of $\mathrm{CB}$ to St.

So, the effects of the concentration of Tween 80 , the pouring velocity, the prior addition of surfactant aqueous solution and the weight ratio of CB to St on the content were investigated.

Table 2 shows the dependence of the content on the operational conditions stated just above.

Table 2(a) shows the content $\left(M_{o}\right)$ calculated on the basis of feed, in which the content changed from $50 \mathrm{wt} \%$ at $R=1 / 1$ to $4.8 \mathrm{wt} \%$ at $R=1 / 20$.

Table 2(b) shows the content $(M)$ measured by changing $R$ under the conditions such as $W c=0.5 \mathrm{~g}, C=1.0 \mathrm{wt} \%$ and $V e=25 \mathrm{ml} / \mathrm{h}$.

The content $(M)$ changed from $49.5 \mathrm{wt} \%$ at $R=1 / 1$ to $2.1 \mathrm{wt} \%$ at $R=1 / 20$, in which the values of $\left(M_{o}-M\right) / M_{o}$ mean the degree of the difference between $M_{o}$ and $M$.

The difference increased with decreasing $R$. From this result, it was found that $\mathrm{CB}$ over the half of $\mathrm{CB}$ added could not be contained. This result may be due to the adhesion of the St droplets on the reactor wall and the baffles.

Table 2(c) shows the content $(M)$ measured by changing the pouring velocity ( $\mathrm{Ve}$ ) under the conditions such as $W c=0.5 \mathrm{~g}, W \mathrm{~s}=0.5 \mathrm{~g}(R=1 / 5)$ and $C=1.0 \mathrm{wt} \%$. 
Table 2. Contents.

\begin{tabular}{|c|c|c|c|c|}
\hline \multicolumn{5}{|c|}{ (a) Content on Basis Feed } \\
\hline \multirow[t]{2}{*}{$R\left(=W_{d} / W_{s}\right)$} & $1 / 1$ & $1 / 5$ & $1 / 10$ & $1 / 20$ \\
\hline & $(0.5 / 0.5)$ & $(0.5 / 2.0)$ & $(0.5 / 5.0)$ & $(0.5 / 10.0)$ \\
\hline$M_{o}[\mathrm{wt} \%]$ & 50 & 16.7 & 9.1 & 4.8 \\
\hline \multicolumn{5}{|c|}{ (b) $W c=0.5 \mathrm{~g}, \mathrm{C}=1.0 \mathrm{wt} \%, V e=25 \mathrm{ml} / \mathrm{h}$} \\
\hline$R$ & $1 / 1$ & $1 / 5$ & $1 / 10$ & $1 / 20$ \\
\hline$M[\mathrm{wt} \%]$ & 49.5 & 13.0 & 6.0 & 2.1 \\
\hline$\left(M_{o}-M\right) / M_{o}(\%)$ & 1.0 & 22 & 34 & 56 \\
\hline \multicolumn{5}{|c|}{ (c) $W c=0.5 \mathrm{~g}, W s=0.5 \mathrm{~g}(R=1 / 5), \mathrm{C}=1.0 \mathrm{wt} \%$} \\
\hline $\mathrm{Ve}$ & 10 & 25 & 50 & 100 \\
\hline$M$ & 16.3 & 13.0 & 10.5 & 9.1 \\
\hline$\left(M_{o}-M\right) / M_{o}(\%)$ & 2.4 & 22 & 37 & 45.5 \\
\hline \multicolumn{5}{|c|}{ (d) $W c=0.5 \mathrm{~g}, W s=0.5 \mathrm{~g}(R=1 / 5), V e=25 \mathrm{ml} / \mathrm{h}$} \\
\hline $\mathrm{C}$ & 0.5 & 1.0 & 1.5 & 2.0 \\
\hline$M[\mathrm{wt} \%]$ & 12.1 & 13.0 & 14.5 & 16.0 \\
\hline$\left(M_{o}-M\right) / M_{o}(\%)$ & 27.5 & 22.0 & 13.2 & 4.2 \\
\hline \multicolumn{5}{|c|}{ Prior Addition } \\
\hline \multicolumn{5}{|c|}{$W c=0.5 \mathrm{~g}, W s=0.5 \mathrm{~g}(R=1 / 5), V e=25 \mathrm{ml} / \mathrm{h}$} \\
\hline $\mathrm{C}$ & 0.5 & 1.0 & 1.5 & 2.0 \\
\hline$M[\mathrm{wt} \%]$ & 13.6 & 14.5 & 15.7 & 16.3 \\
\hline$\left(M_{o}-M\right) / M_{o}(\%)$ & 18.6 & 22.0 & 6.7 & 1.3 \\
\hline
\end{tabular}

The content $(M)$ changed from $16.3 \mathrm{wt} \%$ at $V e=10 \mathrm{ml} / \mathrm{h}$ to $9.1 \mathrm{wt} \%$ at $V e=100$ $\mathrm{ml} / \mathrm{h}$.

It was found that the larger the pouring velocity, the lower the content because of the adhesion of the St droplets.

Table 2(d) shows the content $(M)$ measured by changing the surfactant concentration (C) under the conditions such as $W c=0.5 \mathrm{~g}, W s=0.5 \mathrm{~g}(R=1 / 5), V e=25 \mathrm{ml} / \mathrm{h}$ and the effect of prior addition. The content $(M)$ increased from $12.1 \mathrm{wt} \%$ at $C=0.5$ wt $\%$ to $16.0 \mathrm{wt} \%$ at $C=2.0 \mathrm{wt} \%$. It was found that the higher the concentration, the higher the content because of increase in the stability of the $(\mathrm{S} / \mathrm{O})$ dispersion and the (S/O)/W dispersion. Also, as the value of $\left(M_{o}-M\right) / M_{o}$ is $4.2 \%$ at $C=2.0 \mathrm{wt} \%$, the $\mathrm{St}$ droplets containing CB were effectively used to form PCP.

While, the content with prior addition of a part of surfactant aqueous solution became higher than those without prior addition, because the $(\mathrm{S} / \mathrm{O}) / \mathrm{W}$ dispersion became more stable.

For example, the content increased from 12.1 (without) to 13.6 (with) at $C=0.5 \mathrm{wt} \%$ and from 16.0 (without) to 16.3 (with) at $C=2.0 \mathrm{wt} \%$.

In summary, the content could be changed in the region from $2.1 \%$ to $49.5 \%$ together with the mean diameter of PCPs by the operational conditions. Especially, the content under the operational conditions such as $W c=0.5 \mathrm{~g}, W s=0.5 \mathrm{~g}, V e=25 \mathrm{ml} / \mathrm{h}$ and $\mathrm{C}=$ $2.0 \mathrm{wt} \%$ became nearly equal to the content on the basis of feed. 


\subsection{Formation Mechanism of Polymer Composite Particles}

Figure 9 shows the formation mechanism of PCP presented taking the results obtained into consideration.

At the microencapsulation process, $\mathrm{CB}$ was microencapsulated with the St droplets formed by phase separation, in which according to the weight ratio of $\mathrm{CB}$ to $\mathrm{St}$, a $\mathrm{CB}$ particle was microencapsulated (A1, A2) to form the irregular composite particles or the spherical polymer composite particles and a flocculated $\mathrm{CB}$ powder was microencapsulated (A3, A4) to form the irregular polymer composite particles or the spherical polymer composite particles.

After this process, suspension polymerization was conducted.

At this process, the larger PCPs should be formed due to coalescence between the St droplets containing $\mathrm{CB}$. The spherical polymer composite particles may be formed in the case that the volume of St droplets is larger than that of $\mathrm{CB}$, namely the $\mathrm{CB}$ concentration is low or the pouring velocity is larger as stated above. In order to smoothly proceed the microencapsulation process, it is necessary for the St droplets to be formed so as to contain CB. For this, the surface of $\mathrm{CB}$ is hydrophobic to a certain degree or is charged oppositely to the St droplets.

As CB and the St droplets are charged negatively $-25 \mathrm{mV}$ and $-13 \mathrm{mV}$, respectively, Tween 80 may be suitable to making the surface of $\mathrm{CB}$ hydrophobic in the $(\mathrm{S} / \mathrm{O})$ dispersion and neutralizing the $\zeta$-photential.

Furthermore, Tween 80 makes the $(\mathrm{S} / \mathrm{O})$ dispersion and the $(\mathrm{S} / \mathrm{O}) / \mathrm{W}$ dispersion more stable.

However, Kotamin of cationic surfactant and PVA couldn't satisfactorily stabilize the $(\mathrm{S} / \mathrm{O})$ dispersion and the $(\mathrm{S} / \mathrm{O}) / \mathrm{W}$ dispersion.

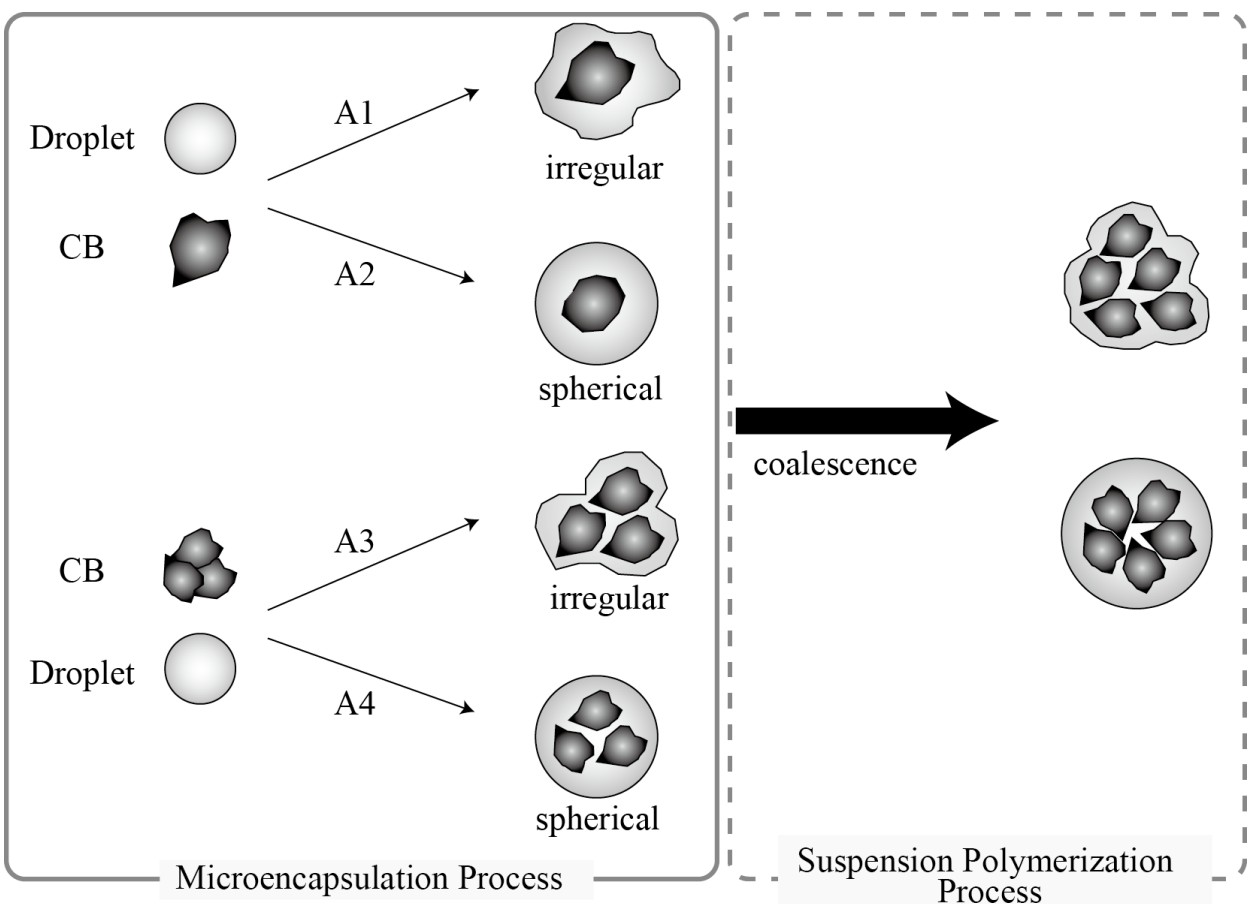

Figure 9. Formation mechanism of polymer composite particles. 
The preparation method developed in this study will be applied to preparing the polymer composite particles composed of polymer and various solid powder.

\section{Conclusions}

It was tried to form the polymer composite particles made of carbon black and polystyrene by use of phase separation followed by suspension polymerization.

The following results were obtained.

1) It was confirmed that the polymer composite particles with the more uniform diameters could be formed by the preparation method presented in this study.

2) The sound spherical polymer composite particles could be formed by addition of nonionic surfactants such as Tween 20 and 80 .

3) The diameters, the morphology and the shape of polymer composite particles were affected by the operational conditions such as the surfactant species and their concentrations, the pouring velocity of surfactant aqueous solution and the weight ratio of $\mathrm{CB}$ to St.

4) The content could be increased with increasing the surfactant concentration and with prior addition of a part of surfactant aqueous solution, and changed from $2.1 \%$ to $49.5 \%$.

\section{References}

[1] Tuan, W., Ren, T., Wu, D., Zhao, H. and Jin, T. (2010) A Novel Preparation Method for Microspheres by Glycerol Modified Solid-in-Oil-in-Water Multi-Emulsion. Polymers for Advanced Technologies, 21, 371-376.

[2] Kim, H., Daniels, E.S., Li, S., Mokkapati, V. and Kardos, K. (2007) Polymer Encapsulation of Yttrium Oxysulfide Phosphorescent Particles via Miniemulsion Polymerization. Journal of Polymer Science: Part A: Polymer Chemistry, 45, 1038-1054. https://doi.org/10.1002/pola.21860

[3] Clarke, N., Hutchings, R.L., Robinson, I., Elder, J.A. and Collins, S.A. (2009) Suspension Polymerization of Poly(Methyl Methacrylate)/Clay Nanocomposites. Journal of Applied Polymer Science, 113, 1307-1315. https://doi.org/10.1002/app.30128

[4] Zhang, Y., Chen, H. and Zou, Q. (2009) Anionic Surfactant for Silica-Coated Polystyrene Composite Microspheres Prepared with Miniemulsion Polymerization. Colloid and Polymer Science, 287, 1221-1227. https://doi.org/10.1007/s00396-009-2089-x

[5] Taguchi, Y. and Tanaka, M. (2014) Microencapsulation of Ascorbic Acid as Redox Initiator with Tripalmitin. International Journal of Material Science, 4, 53-58. https://doi.org/10.14355/ijmsci.2014.0402.02

[6] Taguchi, Y., Tanabe, H., Fuchigami, K. and Tanaka, M. (2015) Microencapsulation of Ascorbic Acid with Tripalmitin by Using Dry Coating Method. Materials Sciences and Applications, 6, 130-139. https://doi.org/10.4236/msa.2015.62016

[7] Shirokawa, K., Taguchi, Y., Yokoyama, H., Ono, F. and Tanaka, M. (2013) Preparation of Temperature and Water Responsive Microcapsules Containing Hydroquinone with Spray Drying Method. Journal of Cosmetics, Dermatological Sciences and Applications, 3, 49-54. https://doi.org/10.4236/jcdsa.2013.33A2012

[8] Taguchi, Y., Yamamoto, R., Saito, N. and Tanaka, M. (2014) Preparation of Microcapsules Containing Aqueous Solution of Azur B with Melting Dispersion Cooling Method and Application to DNA Amplification Detector. Journal of Encapsulation and Adsorption Sciences, 4, 15-24. https://doi.org/10.4236/jeas.2014.41003 
[9] Yuan, H.G., Kalfas, G. and Ray, W.H. (1991) Suspension Polymerization. Journal of Macromolecular Science, Part C: Polymer Reviews, 31, 215-299. https://doi.org/10.1080/15321799108021924

[10] Costoyas, A., Ramos, J. and Forcada, J. (2009) Encapsulation of Silica Nanoparticles by Miniemulsion Polymerization. Journal of Polymer Science: Part A: Polymer Chemistry, 47, 935-948. https://doi.org/10.1002/pola.23212

[11] Koh, H.-D., Changez, M., Lee, J.-P. and Lee, J.-S. (2009) Preparation of Ag-Embedded Polystyrene Nanospheres and Nanocapsules by Miniemulsion Polymerization. Macromolecular Rapid Communications, 30, 1583-1588. https://doi.org/10.1002/marc.200900222

[12] Yomamoto, T., Kawaguchi, K. and Takahashi, Y. (2016) Particle Size Control in the Soap-Free Emulsion Polymerization of Styrene by an Oil-Soluble Initiator with a Weaklyacidic Water-Soluble Initiator. Colloids and Surfaces A: Physicochemical and Engineering Aspects, 502, 1-5. https://doi.org/10.1016/j.colsurfa.2016.04.048

[13] Kimura, I., Taguchi, Y., Yoshii, H. and Tanaka, M. (2001) Encapsulation of Aluminum Flakes by Dispersion Polymerization of Styrene in a Nonaqueous System with Reactive Surfactants. Journal of Applied Polymer Science, 81, 675-683. https://doi.org/10.1002/app.1484

[14] Yasuno, M., Nakajima, M., Iwamoto, S., Maruyama, T., Sugiura, S., Kobayashi, I., Shono, A. and Satoh, K. (2002) Visualization and Characterization of SPG Membrane Emulsification. Journal of Membrane Science, 210, 29-37. https://doi.org/10.1016/S0376-7388(02)00371-X

[15] Chuah, A.M., Kuroiwa, T., Kobayashi, I. and Nakajima, M. (2009) Effect of Chitosan on the Stability and Properties of Modified Lecithin Stabilized Oil-in-Water Monodisperse Emulsion Prepared by Microchannel Emulsification. Food Hydrocolloids, 23, 600-610. https://doi.org/10.1016/j.foodhyd.2008.03.014

[16] Jafari, M.S., He, Y. and Bhandari, B. (2007) Effectiveness of Encapsulating Biopolymers to Produce Sub-Micron Emulsions by High Energy Emulsification Techniques. Food Research International, 40, 862-873. https://doi.org/10.1016/j.foodres.2007.02.002

[17] Erçelebi, E.A. and Ibanoğlu, E.I. (2009) Characterization of Phase Separation Behavior, Emulsion Stability, Rheology, and Microstructure of Egg White-Polysaccharide Mistures. Journal of Food Science, 74, 506-512. https://doi.org/10.1111/j.1750-3841.2009.01252.x

[18] Song, Y. and Shum, H.C. (2012) Monodisperse w/w/w Double Emulsion Induced by Phase Separation. Langmuir, 28, 12054-10259. https://doi.org/10.1021/la3026599

[19] Taguchi, Y., Hosogai, K. and Tanaka, M. (1999) Effect of Solid Powders as Stabilizers on Distributions of Polymer Particle Diameters in Suspension Polymerization. Kagaku Kougaku Ronbunshu, 25, 758-763. https://doi.org/10.1252/kakoronbunshu.25.758

[20] Tanaka, M. and O'shima, E. (1998) Dispersing Behavior of Droplets in Suspension Polymerization of Styrene in a Loop Reactor. The Canadian Journal of Chemical Engineering, 66, 29-35. https://doi.org/10.1002/cjce.5450660104

[21] Taguchi, Y., Saito, N. and Tanaka, M. (1997) Effect of Aqueous Stabilizer in the Preparation of Composite Particles by Suspension Polymerization. Journal of the Japan Society of Colour Material, 8, 503-508. https://doi.org/10.4011/shikizai1937.70.503

[22] Nakamura, D., Yokoyama, H., Taguchi, Y. and Tanaka, M. (2014) Preparation of Microcapsules Containing Water Droplets Stabilized with Solid Powder and Application to Blowing Agent. Materials Sciences and Applications, 5, 20-26.

https://doi.org/10.4236/msa.2014.51003 
Submit or recommend next manuscript to SCIRP and we will provide best service for you:

Accepting pre-submission inquiries through Email, Facebook, LinkedIn, Twitter, etc. A wide selection of journals (inclusive of 9 subjects, more than 200 journals)

Providing 24-hour high-quality service

User-friendly online submission system

Fair and swift peer-review system

Efficient typesetting and proofreading procedure

Display of the result of downloads and visits, as well as the number of cited articles Maximum dissemination of your research work

Submit your manuscript at: http://papersubmission.scirp.org/

Or contact ojcm@scirp.org 